\title{
Perspectives on the clinical utility of allografts for bone regeneration within osseous defects: a narrative review
}

This article was published in the following Dove Press journal:

Orthopedic Research and Reviews

4 April 20II

Number of times this article has been viewed

Larry E Miller ${ }^{1,2}$

Jon E Block ${ }^{2}$

'Miller Scientific Consulting, LLC, Flagstaff, AZ, USA; ' 2 Jon E. Block, Ph.D., Inc., San Francisco, CA, USA
Correspondence: Jon E Block

2210 Jackson Street, Suite 40I,

San Francisco, CA 941 15, USA

$\mathrm{Tel}+\mathrm{I}$ 4| 5-775-7947

$\mathrm{Fax}+\mathrm{I}$ 4I5-928-0765

Email jonblock@jonblockphd.com
Abstract: A variety of bone grafts and bone graft substitutes is available for treatment of osseous defects although adequate reconstruction of the residual void following fracture, arthroplasty, or tumor/cyst resection remains a therapeutic challenge. This narrative review evaluates the peer-reviewed literature and examines relevant outcomes in patients treated with bone grafts and bone graft substitutes for surgical management of osseous defects. Although autograft, xenograft, and ceramic bone graft substitutes are used for a variety of orthopedic applications, they have distinct limitations in clinical practice. Bone allograft material is a safe and effective adjunct to treatment of osseous defects.

Keywords: allograft, bone graft, osseous defect

\section{Introduction}

Bone is the second most commonly transplanted tissue in the human body with 600,000 graft procedures performed each year. ${ }^{1}$ A wide variety of bone grafts and bone graft substitutes, each with distinctly different characteristics, is available to the orthopedic surgeon for various reconstructive procedures including arthrodesis, traumatic fracture management, maxilllofacial implants, and cavitary filling following tumor and cyst resection and curettage. Treatment of osseous defects with bone grafting is an underappreciated field that can potentially help patients realize a quicker return to normal activities. Unfortunately, adequate reconstruction of the residual void following fracture, arthroplasty, or tumor/cyst resection remains a therapeutic challenge. Each bone graft option has a unique set of benefits and risks that must be considered in relation to the particular pathology in order to achieve the best possible outcome.

There are 4 desirable characteristics of any bone graft: osteoconduction, osteoinduction, osteointegration, and osteogenesis. Osteoconduction refers to the ability of a bone graft to act as a scaffold to facilitate bone growth over its surface, within its matrix, or both. Osteoinduction is the capacity to recruit mesenchymal cells from surrounding host tissue and to stimulate them to differentiate into osteoblasts. Osteointegration is the ability to chemically bond to the surface of bone in the absence of an intervening layer of fibrous tissue. Osteogenesis describes the ability of a graft to produce new bone de novo, mediated by the transplant of osteogenic precursor cells within the graft material, at the recipient site., ${ }^{2,3}$

Historically, autografts have served as the mainstay bone graft of choice since autologous bone is inherently capable of osteoconduction, osteoinduction, and osteogenesis. Despite the fact that autografts have demonstrated acceptable 
effectiveness, a large body of evidence suggests that the clinical morbidity resulting from harvesting bone from the patient's own hip is substantial and may outweigh the benefits of this procedure. ${ }^{4-7}$ Complications such as superficial nerve damage, vascular injury, iliac fracture, infection, and chronic donor site pain occur in $10 \%$ to $50 \%$ of patients who undergo autograft harvest. ${ }^{5,6}$ Furthermore, the quantity of bone available for harvest from the iliac crest is limited and regeneration of the residual defect is slow, ${ }^{8}$ which hinders the widespread use of this treatment option, particularly for large osseous defects. Overall, the unacceptably high complication risk and prolonged procedure time associated with autograft harvesting has caused skepticism about this graft material among patients and physicians alike.

Another option, xenografts (or heterologous) bone grafts are derived from nonhuman species (primarily bovine and porcine) and represent an alternative to autologous harvesting. Few human studies with xenografts, aside from spinal and maxillofacial applications, have been conducted. ${ }^{9}$ Although there has been a recent concerted effort to improve the biocompatability of xenografts, ${ }^{10-12}$ significant risks remain including pathogen transmission, immunogenic rejection, prolonged graft integration, and fracture. ${ }^{13-15}$ Despite these risks, xenografts continue to be utilized on a limited basis for the treatment of osseous defects primarily because of their abundant supply and their satisfactory osteoconductive characteristics.

Additionally, ceramic bone graft substitutes such as hydroxyapatite, calcium sulfate, and calcium phosphates have been used with increasing frequency over the last decade in the adjunctive management of osseous defects mainly due to their osteoconductive properties. ${ }^{16}$ However, the porosity of these materials has a detrimental impact on mechanical strength, which may increase fracture risk. Furthermore, while biocompatibility of ceramics is generally acceptable, these grafts lack osteoinductive and osteogenic properties unless combined with autologous marrow or other bone growth factors. ${ }^{17}$

Finally, allografts, which are obtained from deceased donors, are used for a wide variety of orthopedic reconstructive applications and have osteoconductive, osteointegrative, and osteoinductive properties, especially when demineralized. ${ }^{18}$ Allografts overcome the primary limitations associated with autografts, namely that the risk of donor site morbidity is eliminated and that they are readily available in large quantities. However, processed allograft bone possesses no osteogenic properties since it contains no live cells.

Given that each type of bone graft has distinct characteristics (Table 1), it is important to review the research that has been
Table I Characteristics of bone grafts and bone graft substitutes

\begin{tabular}{lllll}
\hline Variable & Allograft & Autograft & Xenograft & Ceramics \\
\hline Osteoconduction & +++ & ++ & ++ & ++ \\
Osteoinduction & ++ & ++ & + & - \\
Osteointegration & ++ & +++ & ++ & +++ \\
Osteogenesis & - & +++ & - & - \\
\hline
\end{tabular}

Notes: +++, excellent; ++, average; +, poor; -, none.

performed on these materials to determine how these physical properties translate into clinical application. This narrative review evaluates the peer-reviewed literature and examines relevant outcomes in patients treated with bone grafts and bone graft substitutes for surgical management of osseous defects.

\section{Clinical outcomes}

\section{Autograft}

Clinical experience with autografts for osseous defect treatment has yielded mixed results. Radiographic and clinical outcomes at the recipient site are usually, but not always, positive. Rajan and colleagues treated 75 patients with comminuted distal radius fractures with either autograft or allograft. ${ }^{6}$ Clinical and radiographic outcomes 1 year following surgery were similar in both groups. Ring and colleagues treated 35 patients with autografts and plate fixation for diaphyseal forearm nonunions and segmental defects. After 6 months, all patients were healed and none required a follow-up procedure. ${ }^{19}$ Autografts also yield good-toexcellent results in $90 \%$ of cystic talus lesions. ${ }^{20}$

However, several trials have reported mixed outcomes with autologous bone grafting due, in part, to the lack of immediate structural support. Several studies have concluded that union rates following comminuted forearm fracture were similar in patients treated with or without autograft. ${ }^{21,22}$ Gershuni and Pinsker ${ }^{23}$ treated 40 tibial nonunions with autograft and cast immobilization. Despite a union rate of $85 \%$, significant tibial deformity persisted. Adani et $\mathrm{al}^{24}$ treated 13 patients with autograft for humeral nonunion. Four (31\%) patients required additional bone grafting after only 6 months follow-up.

In addition to these equivocal clinical outcomes, the overwhelming limitation of this bone grafting method is the significant and persistent morbidity related to donor site harvesting, most commonly at the iliac crest. ${ }^{7}$ The most common complication is postoperative pain at the donor site, occurring in $50 \%$ of patients and persisting through 1 year in up to $29 \%$ of patients. ${ }^{5,6}$ Additional commonly reported problems include nerve injury, hemorrhage, fracture, and hernia. ${ }^{25-28}$ Due to this significant morbidity, autologous bone grafting 
has become less desirable in recent years with a concerted effort to identify satisfactory grafting alternatives.

\section{Xenograft}

Few human studies of osseous defect treatment with xenografts have been conducted. ${ }^{9}$ Schultheiss et al observed delayed incorporation of bovine cancellous blocks for reconstruction of thoracolumbar fractures compared to autologous tricortical iliac crest bone grafts. ${ }^{29}$ Liu et al ${ }^{30}$ treated 65 patients with xenograft predominantly for long bone fractures and tumor resection. Graft infection was observed in $8 \%$ of cases and graft rejection with immunosuppressive treatment was common. Charalambides and coworkers ${ }^{31}$ treated 27 patients with xenograft and autograft following hip revision surgery. After a mean 2.5 year follow-up, 3 grafts did not incorporate, 3 patients had graft infection, and 1 patient suffered a deep prosthesis infection. Levai et $\mathrm{al}^{32}$ used bovine xenograft in 31 patients for treatment of tibial osteotomy defects. At 2.5 years follow-up, 5 (16\%) patients experienced local discharge or infection. These authors concluded that xenografts have an unpredictable radiographic and histological outcome, and when also considering the high incidence of local complications, they opined that use of xenografts in humans should be discontinued. Overall, xenografts processed with currently available techniques are not recommended to fill cavitary defects due to the excessive risk of graft rejection and infection.

\section{Ceramic bone graft substitutes}

As a whole, ceramic bone graft substitutes result in acceptable, but not excellent, long-term clinical outcomes. ${ }^{16}$ Coralline hydroxyapatite has demonstrated clinical outcomes similar to that of autograft in treating tibial plateau fractures. ${ }^{33}$ However, the brittleness of this material makes handling difficult and often results in fragmentation while impacting this material into the defect. Several authors have reported excellent results with calcium phosphate for traumatic fractures or cavitary filling after excision of tumors or cysts. ${ }^{34,35}$ Anker and colleagues ${ }^{36}$ reported that tricalcium phosphate incorporated well into small cavitary defects but incorporation was incomplete after 1 year in large defects $(\geq 43 \mathrm{~cm})$.

Calcium phosphate cement has much greater compressive strength versus other ceramics. A prospective trial of 110 patients with distal radius fractures found that calcium phosphate cement yields a greater frequency of satisfactory results and fewer malunions when used to fill metaphyseal defects versus closed reduction and cast immobilization. ${ }^{37}$ A similar study in 52 menopausal, osteoporotic women with unstable distal radius fractures showed that use of calcium phosphate cement to supplement pin and screw fixation maintained the reduction of unstable distal radius fractures and yielded superior clinical outcomes versus percutaneous pinning. ${ }^{38}$ However, a randomized study of 323 patients with distal radius fractures treated with or without calcium phosphate cement for metaphyseal defect filling showed no group differences in grip strength, range of motion, or quality of life at 3 months and 1 year. ${ }^{39}$ Furthermore, extravasation into the surrounding soft tissues occurred in $70 \%$ of patients treated with calcium phosphate cement. Painful soft tissue reactions have also been reported in up to $20 \%$ of patients following calcium phosphate cement injection. ${ }^{40}$

Calcium sulfate use for osseous defects remains controversial. This material undergoes dissolution within 4 to 12 weeks, which is too rapid to provide a long-term framework to support osteoconduction. Calcium sulfate ceramics undergo phagocytosis, which contributes to this accelerated material biodegradation. ${ }^{41}$ Consequently, outcomes of tibial defect treatment with calcium sulfate are similar to no treatment at all. ${ }^{42}$ Collagraft, which is a composite of bovine collagen and a biphasic ceramic (60\% hydroxyapatite and $40 \%$ tricalcium phosphate), was shown to perform similarly to autograft in a randomized controlled trial of 325 patients with long bone fractures followed for 2 years, although allergic response to the bovine protein occurs in 1 out of 10 cases. $^{43}$

\section{Allograft}

Gajiwala ${ }^{44}$ reported his experience with morsellized allografts in patients with tumor defects, primarily of the femur and tibia. Of the patients who were available for follow-up, all patients (21 of 21) had complete incorporation of the graft after 6 to 9 months. Temple and Malinin ${ }^{45}$ used small allogeneic cortical graft particles to treat 97 patients with osseous tumors. After an average of 3 years follow-up, both graft incorporation and consolidation rates were over $90 \%$. Lasanianos et a $1^{46}$ used freeze-dried cancellous allograft following surgical treatment of impacted tibial plateau fractures. After a mean 13 months of follow-up, 21 of 23 (91\%) patients had a good or excellent clinical and radiographic outcome with no major complications. Shih and colleagues ${ }^{47}$ treated 104 patients with long bone defects with curettage and allografts. Good or excellent functional results were reported in $97 \%$ of patients after 4 years with no local recurrence or graft fracture and only a single complication. Treatment of intercalary long bone defects with allograft has consistently shown successful outcomes without the need for adjunctive follow-up procedures in $81 \%$ to $85 \%$ of cases. ${ }^{48-50}$ Overall, allografts yield excellent 
clinical outcomes with good versatility in cavitary defects across various anatomic locations.

\section{Discussion}

Overall, it is difficult to strictly compare radiographic and clinical success with treatment by different types of bone grafts for osseous defects, primarily due to the varying types and locations of defects encountered in clinical practice and the lack of comparative studies. Regardless, several global conclusions may be drawn from the breadth of literature on this topic.

Autologous bone grafting has long been considered the gold standard for treatment of osseous defects. The iliac crest is the most common site for obtaining autologous bone mainly due to ease of access in obtaining the graft material. The completeness of incorporation, rapid healing rate, and inherent biocompatibility of autografts are ideal. However, the frequency and severity of harvest site morbidity makes autologous bone an arguably unsatisfactory choice for osseous defect treatment, especially considering that all other bone grafting choices are free from this potential complication. Obtaining large amounts of autograft material is exceedingly difficult and is very likely to result in prolonged postoperative pain and ambulation difficulties since the risk of morbidity following autologous bone grafting is in direct proportion to the volume of excised bone. ${ }^{51}$

Despite wide application in animal models and maxillofacial procedures in humans, xenografts are used on a limited basis for osseous defect reconstruction, primarily because more effective and less risky options exist. The porosity of xenografts promotes osteoconduction, although this characteristic also compromises the initial stability of the graft. ${ }^{52}$ Furthermore, the required processing of this tissue (eg, autoclaving) reduces infection risk but has the detrimental effect of lowering the graft's resistance to compression by up to $70 \% .{ }^{53}$ Xenografts also have great potential for rejection and infection transfer to the recipient. In addition, the necessity of immunosuppressive therapy and the associated side effects currently make xenografts an overall poor choice for treatment of osseous defects. Lastly and perhaps most importantly, there is a paucity of clinical study results on xenografts apart from maxillofacial applications and, therefore, little is known about the long-term performance of these tissues in the treatment of osseous defects. ${ }^{29}$ Given the fact that delayed xenograft rejection is an ever-present risk, ${ }^{13}$ xenograft use represents a treatment option that presents significant known and unknown risks to the patient. In fact, several authors have concluded that xenograft material should not be used for treatment of osseous defects because of the unacceptably high infection and graft rejection rates..$^{30,31}$

Ceramic bone graft substitutes have somewhat varying biomechanical properties, but as a whole, suffer from common limitations. These synthetic bone analogs have variable biocompatibility, often heal incompletely, and can be expensive. ${ }^{45}$ Hydroxyapatite is brittle with little tensile strength and use should be limited to defects that are not subjected to weight bearing and where bending, torsion, and sheer are minimized. Furthermore, the bending strength of incorporated hydroxyapatite in cortical bone is only $10 \%$ of cortical bone itself and, therefore, the bone graft may never be able to withstand normal physiological loads in these areas. ${ }^{54}$ Finally, residual hydroxyapatite material remains unincorporated for 10 years or more following grafting. ${ }^{55}$ Calcium phosphate also suffers from inherent weakness under load and has an extremely slow resorption rate $(30 \%$ to $60 \%$ at 1 year). ${ }^{39}$ Tricalcium phosphate is equally slow to resorb and is very brittle. Calcium sulfate absorbs very quickly (4 to 12 weeks) although the resorption occurs faster than bone growth occurs, which results in structural instability and weakness under loading. As a whole, ceramic bone graft substitutes have limited mechanical properties and must generally be used in conjunction with internal or external fixation devices. Furthermore, there is little evidence of their effectiveness, particularly for large cavitary defects. ${ }^{56}$ Finally, the cost of ceramic bone graft substitutes can be high, especially for treatment of large defects.

\section{Allografts: the bone graft of choice}

Allograft bone has a 50-year history of use for various orthopedic indications. ${ }^{57}$ Allografts have become the bone graft of choice for treatment of osseous defects because of their distinct advantages versus other alternatives. ${ }^{58}$ The primary advantages are lack of donor site morbidity, simple technique with short operative time, sufficient supply to treat even the largest bone voids, and excellent patient outcomes. Allografts are of particular benefit in the case of large bone defects that require structural support and when inadequate autologous graft volume is available. Furthermore, properly processed allografts have the same structure as native bone and exhibit a uniform ability to withstand stress and intraoperative handling. Allografts are widely available and are quite versatile since the shape, contour, and mineral density can be modified to the particular clinical indication. A comprehensive clinical evaluation of the performance of bone grafts and bone graft substitutes for osseous defect treatment is provided in Table 2 . 
Table 2 Clinical evaluation of osseous defect treatment with allograft, autograft, xenograft, and ceramics

\begin{tabular}{lllll}
\hline Variable & Allograft & Autograft & Xenograft & Ceramics \\
\hline Structural support & +++ & ++ & ++ & + \\
Cost effectiveness & +++ & ++ & + & ++ \\
Procedural safety & +++ & + & + & ++ \\
Long-term safety & +++ & + & $?$ & $?$ \\
Long-term & +++ & ++ & $?$ & + \\
effectiveness & & & & \\
\hline
\end{tabular}

Notes: +++, excellent; ++, average; +, poor; ?, unknown.

Despite the favorable performance of allograft compared with other bone graft materials, allograft suffers from several limitations. Allograft fracture or nonunion has been reported in $15 \%$ to $20 \%$ of grafts, primarily due to limited revascularization. ${ }^{59}$ In large defects, poor anatomical matching between the graft and the host defect can alter joint kinematics and load distribution, which may accelerate bone resorption or joint degeneration. Allograft infection has been reported in $6 \%$ to $13 \%$ of cases, with the proximal tibia most commonly affected. ${ }^{59,60}$ Infection risk can be lowered by employing aseptic processing steps such as soaking the graft in an antibiotic solution at the time of harvest and procurement.

There is a common misperception about the risk for disease transmission from the host to the donor. Although the risk is extremely low, disease transmission is possible from allografts although no cases have ever been documented with irradiation sterilized allografts. Careful selection of an American Association of Tissue Banks (AATB) -accredited bone bank is paramount to attain safe and effective allograft tissue. Such bone allografts undergo strict screening and recovery processes that conform to US Food and Drug Administration and AATB standards.

The process to determine donor eligibility begins with a comprehensive screening program that includes a series of standardized questions, physical examinations, and review of medical records and autopsy reports. The final approval for allograft donation is determined by a licensed physician after a thorough review of these records. Donors are automatically excluded if toxin exposure, bone disease, autoimmune disease, or infectious disease is detected. If a donor meets all eligibility criteria, the tissue is promptly removed from the donor and cultures are performed to further confirm the absence of disease. Donors must also test negative for indications of infective potential, which includes testing for HIV, hepatitis $\mathrm{C}$, hepatitis B surface antigen, and total antibody to hepatitis B core antigen. In addition, bone allografts are typically disinfected through a variety of physical and chemical solution processes.

\section{Conclusion}

Based on a narrative review of the peer-reviewed literature, we conclude that bone allograft material is a safe and effective adjunct to treatment of osseous defect. Although autograft, xenograft, and ceramic bone graft substitutes are used for a variety of orthopedic applications, these materials have distinct limitations in clinical practice. The use of allografts obtained from AATB-certified bone banks can improve treatment success for these procedures. Overall, allografts are safe and effective bio-implants and represent the gold standard for treatment of osseous defects.

\section{Acknowledgments}

The authors thank Mr. Randy Asher for graphical assistance. LifeNet Health (Virginia Beach, VA, USA) provided funding for development of this paper.

\section{Disclosure}

The authors declare no conflicts of interest.

\section{References}

1. Marino JT, Ziran BH. Use of solid and cancellous autologous bone graft for fractures and nonunions. Orthop Clin North Am. 2010;41(1):15-26. table of contents.

2. Costantino PD, Friedman CD. Synthetic bone graft substitutes Otolaryngol Clin North Am. 1994;27(5):1037-1074.

3. Cypher TJ, Grossman JP. Biological principles of bone graft healing. J Foot Ankle Surg. 1996;35(5):413-417.

4. Conway JD. Autograft and nonunions: morbidity with intramedullary bone graft versus iliac crest bone graft. Orthop Clin North Am. 2010;41(1):75-84. table of contents.

5. Fernyhough JC, Schimandle JJ, Weigel MC, Edwards CC, Levine AM. Chronic donor site pain complicating bone graft harvesting from the posterior iliac crest for spinal fusion. Spine (Phila Pa 1976). 1992;17(12):1474-1480.

6. Rajan GP, Fornaro J, Trentz O, Zellweger R. Cancellous allograft versus autologous bone grafting for repair of comminuted distal radius fractures: a prospective, randomized trial. J Trauma. 2006;60(6): 1322-1329.

7. Russell JL, Block JE. Surgical harvesting of bone graft from the ilium: point of view. Med Hypotheses. 2000;55(6):474-479.

8. Montgomery DM, Moed BR. Cancellous bone donor site regeneration. J Orthop Trauma. 1989;3(4):290-294.

9. Block JE, Poser J. Does xenogeneic demineralized bone matrix have clinical utility as a bone graft substitute? Med Hypotheses. 1995; 45(1):27-32.

10. Athanasiou VT, Papachristou DJ, Panagopoulos A, Saridis A, Scopa CD, Megas P. Histological comparison of autograft, allograftDBM, xenograft, and synthetic grafts in a trabecular bone defect: an experimental study in rabbits. Med Sci Monit. 2010;16(1): BR24-BR31.

11. Bansal MR, Bhagat SB, Shukla DD. Bovine cancellous xenograft in the treatment of tibial plateau fractures in elderly patients. Int Orthop. 2009;33(3):779-784.

12. Develioglu H, Unver Saraydin S, Kartal U. The bone-healing effect of a xenograft in a rat calvarial defect model. Dent Mater J. 2009; 28(4):396-400.

13. Hancock WW. Delayed xenograft rejection. World J Surg. 1997;21(9): 917-923. 
14. Perico N, Benigni A, Remuzzi G. Xenotransplantation in the 21 st century. Blood Purif. 2002;20(1):45-54.

15. Cook EA, Cook JJ. Bone graft substitutes and allografts for reconstruction of the foot and ankle. Clin Podiatr Med Surg. 2009;26(4): 589-605.

16. Block JE, Thorn MR. Clinical indications of calcium-phosphate biomaterials and related composites for orthopedic procedures. Calcif Tissue Int. 2000;66(3):234-238.

17. Inoue O, Ibaraki K, Shimabukuro H, Shingaki Y. Packing with highporosity hydroxyapatite cubes alone for the treatment of simple bone cyst. Clin Orthop Relat Res. 1993;293(8):287-292.

18. Moore WR, Graves SE, Bain GI. Synthetic bone graft substitutes. ANZ J Surg. 2001;71(6):354-361.

19. Ring D, Allende C, Jafarnia K, Allende BT, Jupiter JB. Ununited diaphyseal forearm fractures with segmental defects: plate fixation and autogenous cancellous bone-grafting. J Bone Joint Surg Am. 2004;86-A(11):2440-2445.

20. Scranton PE Jr, Frey CC, Feder KS. Outcome of osteochondral autograft transplantation for type- $\mathrm{V}$ cystic osteochondral lesions of the talus. J Bone Joint Surg Br. 2006;88(5):614-619.

21. Wright RR, Schmeling GJ, Schwab JP. The necessity of acute bone grafting in diaphyseal forearm fractures: a retrospective review. J Orthop Trauma. 1997;11(4):288-294.

22. Wei SY, Born CT, Abene A, Ong A, Hayda R, DeLong WG Jr. Diaphyseal forearm fractures treated with and without bone graft. $J$ Trauma. 1999;46(6):1045-1048.

23. Gershuni DH, Pinsker R. Bone grafting for nonunion of fractures of the tibia: a critical review. J Trauma. 1982;22(1):43-49.

24. Adani R, Delcroix L, Tarallo L, Baccarani A, Innocenti M. Reconstruction of posttraumatic bone defects of the humerus with vascularized fibular graft. J Shoulder Elbow Surg. 2008;17(4):578-584.

25. Buddecke DE Jr, Lile LN, Barp EA. Bone grafting. Principles and applications in the lower extremity. Clin Podiatr Med Surg. 2001;18(1): 109-145, vi.

26. Keller EE, Triplett WW. Iliac bone grafting: review of 160 consecutive cases. J Oral Maxillofac Surg. 1987;45(1):11-14.

27. Schulhofer SD, Oloff LM. Iliac crest donor site morbidity in foot and ankle surgery. J Foot Ankle Surg. 1997;36(2):155-158, discussion 161.

28. Arrington ED, Smith WJ, Chambers HG, Bucknell AL, Davino NA. Complications of iliac crest bone graft harvesting. Clin Orthop Relat Res. 1996;329(8):300-309.

29. Schultheiss M, Sarkar M, Arand M, et al. Solvent-preserved, bovine cancellous bone blocks used for reconstruction of thoracolumbar fractures in minimally invasive spinal surgery-first clinical results. Eur Spine J. 2005;14(2):192-196.

30. Liu Z, Xia L, Gong W. Preliminary report of xenogenic bone graft for sixty-five cases. Zhongguo Xiu Fu Chong Jian Wai Ke Za Zhi. 1998; 12(5):309-311.

31. Charalambides C, Beer M, Cobb AG. Poor results after augmenting autograft with xenograft (Surgibone) in hip revision surgery: a report of 27 cases. Acta Orthop. 2005;76(4):544-549.

32. Levai JP, Bringer O, Descamps S, Boisgard S. Xenograft-related complications after filling valgus open wedge tibial osteotomy defects. Rev Chir Orthop Reparatrice Appar Mot. 2003;89(8): 707-711.

33. Bucholz RW, Carlton A, Holmes R. Interporous hydroxyapatite as a bone graft substitute in tibial plateau fractures. Clin Orthop Relat Res. 1989;240(3):53-62.

34. Bucholz RW, Carlton A, Holmes RE. Hydroxyapatite and tricalcium phosphate bone graft substitutes. Orthop Clin North Am. 1987;18(2):323-334.

35. McAndrew MP, Gorman PW, Lange TA. Tricalcium phosphate as a bone graft substitute in trauma: preliminary report. J Orthop Trauma. 1988;2(4):333-339.

36. Anker CJ, Holdridge SP, Baird B, Cohen H, Damron TA. Ultraporous beta-tricalcium phosphate is well incorporated in small cavitary defects. Clin Orthop Relat Res. 2005;434(5):251-257.
37. Sanchez-Sotelo J, Munuera L, Madero R. Treatment of fractures of the distal radius with a remodellable bone cement: a prospective, randomised study using Norian SRS. J Bone Joint Surg Br. 2000;82(6): 856-863.

38. Zimmermann R, Gabl M, Lutz M, Angermann P, Gschwentner M, Pechlaner S. Injectable calcium phosphate bone cement Norian SRS for the treatment of intra-articular compression fractures of the distal radius in osteoporotic women. Arch Orthop Trauma Surg. 2003;123(1):22-27.

39. Cassidy C, Jupiter JB, Cohen M, et al. Norian SRS cement compared with conventional fixation in distal radial fractures. A randomized study. J Bone Joint Surg Am. 2003;85-A(11):2127-2137.

40. Welkerling H, Raith J, Kastner N, Marschall C, Windhager R. Painful soft-tissue reaction to injectable Norian SRS calcium phosphate cement after curettage of enchondromas. J Bone Joint Surg Br. 2003;85(2):238-239.

41. Lu J, Descamps M, Dejou J, et al. The biodegradation mechanism of calcium phosphate biomaterials in bone. J Biomed Mater Res. 2002; 63(4):408-412.

42. Petruskevicius J, Nielsen S, Kaalund S, Knudsen PR, Overgaard S. No effect of Osteoset, a bone graft substitute, on bone healing in humans: a prospective randomized double-blind study. Acta Orthop Scand. 2002;73(5):575-578.

43. Chapman MW, Bucholz R, Cornell C. Treatment of acute fractures with a collagen-calcium phosphate graft material. A randomized clinical trial. J Bone Joint Surg Am. 1997;79(4):495-502.

44. Gajiwala AL. Setting up a Tissue Bank in India: The Tata Memorial Hospital Experience. Cell Tissue Bank. 2003;4(2-4):193-201.

45. Temple HT, Malinin TI. Microparticulate cortical allograft: an alternative to autograft in the treatment of osseous defects. Open Orthop J. 2008;2:91-96.

46. Lasanianos N, Mouzopoulos G, Garnavos C. The use of freeze-dried cancelous allograft in the management of impacted tibial plateau fractures. Injury. 2008;39(10):1106-1112.

47. Shih HN, Chen YJ, Huang TJ, Hsu KY, Hsu RW. Semistructural allografting in bone defects after curettage. J Surg Oncol. 1998;68(3): 159-165.

48. Donati D, Capanna R, Campanacci D, et al. The use of massive bone allografts for intercalary reconstruction and arthrodeses after tumor resection. A multicentric European study. Chir Organi Mov. 1993;78(2):81-94.

49. Ortiz-Cruz E, Gebhardt MC, Jennings LC, Springfield DS, Mankin HJ. The results of transplantation of intercalary allografts after resection of tumors. A long-term follow-up study. J Bone Joint Surg Am. 1997;79(1):97-106.

50. Muscolo DL, Ayerza MA, Aponte-Tinao L, Ranalletta M, Abalo E. Intercalary femur and tibia segmental allografts provide an acceptable alternative in reconstructing tumor resections. Clin Orthop Relat Res. 2004;426(9):97-102.

51. Pape HC, Evans A, Kobbe P. Autologous bone graft: properties and techniques. J Orthop Trauma. 2010;24 Suppl 1:S36-S40.

52. Su-Gwan K, Hak-Kyun K, Sung-Chul L. Combined implantation of particulate dentine, plaster of Paris, and a bone xenograft (Bio-Oss) for bone regeneration in rats. J Craniomaxillofac Surg. 2001;29(5):282-288.

53. Viceconti M, Toni A, Brizio L, Rubbini L, Borrelli A. The effect of autoclaving on the mechanical properties of bank bovine bone. Chir Organi Mov. 1996;81(1):63-68.

54. Bucholz RW. Nonallograft osteoconductive bone graft substitutes. Clin Orthop Relat Res. 2002;395(2):44-52.

55. Hak DJ. The use of osteoconductive bone graft substitutes in orthopaedic trauma. J Am Acad Orthop Surg. 2007;15(9):525-536.

56. Finkemeier CG. Bone-grafting and bone-graft substitutes. J Bone Joint Surg Am. 2002;84-A(3):454-464.

57. Bostrom MP, Yang X, Kennan M, Sandhu H, Dicarlo E, Lane JM. An unexpected outcome during testing of commercially available demineralized bone graft materials: how safe are the nonallograft components? Spine (Phila Pa 1976). 1 2001;26(13):1425-1428. 
58. Capanna R, Campanacci DA, Belot N, et al. A new reconstructive technique for intercalary defects of long bones: the association of massive allograft with vascularized fibular autograft. Long-term results and comparison with alternative techniques. Orthop Clin North Am. 2007;38(1):51-60, vi.
59. Delloye C, Cornu O, Druez V, Barbier O. Bone allografts: What they can offer and what they cannot. J Bone Joint Surg Br. 2007; 89(5):574-579.

60. Mankin HJ, Hornicek FJ, Raskin KA. Infection in massive bone allografts. Clin Orthop Relat Res. 2005(432):210-216.

\section{Publish your work in this journal}

Orthopedic Research and Reviews is an international, peer-reviewed, open access journal focuses on the patho-physiology of the musculoskeletal system, trauma, surgery and other corrective interventions to restore mobility and function. Advances in new technologies, materials, techniques and pharmacological agents are particularly welcome. The journal welcomes

\section{Dovepress}

original research, clinical studies, reviews \& evaluations, expert opinion and commentary, case reports and extended reports. The manuscript management system is completely online and includes a very quick and fair peer-review system, which is all easy to use. Visit http://www.dovepress. com/testimonials.php to read real quotes from published authors.

Submit your manuscript here: http://www.dovepress.com/orthopedic-research-and-reviews-journal 